\title{
Reconstruction of a large calvarial traumatic defect using a custom-made porous hydroxyapatite implant covered by a free latissimus dorsi muscle flap in an 11-year-old patient
}

\author{
*Anne Morice, MD, ${ }^{1,5}$ Frédéric Kolb, MD, ${ }^{2}$ Arnaud Picard, MD, PhD, ${ }^{1,3,4}$ Natacha Kadlub, MD, PhD, ${ }^{1,3,4}$ \\ and Stéphanie Puget, MD, PhD
}

1APHP, Hôpital Necker Enfants Malades, Service de chirurgie maxillo-faciale, Paris; ${ }^{2}$ Institut Gustave Roussy, Département de cancérologie cervico-faciale, Service de chirurgie plastique, Villejuif; ${ }^{3}$ Université Paris Descartes, Paris; ${ }^{4}$ Centre de références des malformations de la face et de la cavité buccale, Paris; and ${ }^{5}$ Department of Neurosurgery, Necker Hospital, Université Paris Descartes, Sorbonne Paris Cité, Paris, France

\begin{abstract}
Reconstruction of complex skull defects requires collaboration between neurosurgeons and plastic surgeons to choose the most appropriate procedure, especially in growing children. The authors describe herein the reconstruction of an extensive traumatic bone and soft tissue defect of the cranial vault in an 11-year-old boy. The size of the defect, quality of the tissues, and patient's initial condition required a 2-stage approach. Ten months after an initial emergency procedure in which lacerated bone and soft tissue were excised, reconstruction was performed. The bone defect, situated on the left frontoparietal region, was $85 \mathrm{~cm}^{2}$ and was filled by a custom-made porous hydroxyapatite implant. The quality of the overlying soft tissue did not allow the use of classic local and locoregional coverage techniques. A free latissimus dorsi muscle flap branched on the contralateral superficial temporal pedicle was used and left for secondary healing to take advantage of scar retraction and to minimize alopecia. Stable well-vascularized implant coverage as well as an esthetically pleasing skull shape was achieved. Results in this case suggest that concomitant reconstruction of large calvarial defects by cranioplasty with a custom-made hydroxyapatite implant covered by a free latissimus dorsi muscle flap is a safe and efficient procedure in children, provided that there is no underlying infection of the operative site.
\end{abstract}

http://thejns.org/doi/abs/10.3171/2016.8.PEDS1653

KEY WORDS traumatic skull defects; scalp scars; cranioplasty; custom-made hydroxyapatite implant; free latissimus dorsi muscle flap; surgical technique; trauma

A CCIDENTAL cranial vault trauma is often associated with facial injuries and ranges from small lacerations to extensive life-threatening damage. Patients with mild injury can be managed conservatively, whereas extensive trauma may require emergency salvage surgery to take care of intracranial lesions associated with compound depressed fracture and/or intracranial hematoma with refractory intracranial hypertension. Some cases require decompressive craniectomy (DC) concomitant with dural lacerations repair. While effective in treating intracranial hypertension, it can induce several complications including herniation of the cortex through bone defect, subdural effusion, seizure, ${ }^{12}$ and syndrome of the tre- phined. ${ }^{15}$ A secondary cranioplasty $(\mathrm{CP})$ is then indicated to limit the symptoms of the syndrome of the trephined, restore harmonious skull contours, and protect the brain. However, reconstruction of the vertex may become difficult particularly if traumatic injuries are associated with extensive bone and soft tissue defects. Complications after CP are reported in 10\%-40\% of patients $\mathrm{s}^{5,9,17,29}$ and are most often caused by infection (up to $31.8 \%$ ).$^{30}$ The high rate of local infection after $\mathrm{CP}$ may be explained by the instability of soft tissue coverage. The most common risk factors are under-tension closure, scar retraction, and soft tissue laceration modifying skin vascularization. All of these factors increase the risk of implant exposure.

ABBREVIATIONS CP = cranioplasty; $\mathrm{DC}=$ decompressive craniectomy; $\mathrm{FRC}=$ glass fiber-reinforced composite; $\mathrm{HA}=$ hydroxyapatite; $\mathrm{PEEK}=$ polyetheretherketone; PMMA = polymethylmethacrylate.

SUBMITTED January 25, 2016. ACCEPTED August 3, 2016.

INCLUDE WHEN CITING Published online October 28, 2016; DOI: 10.3171/2016.8.PEDS1653.

* Drs. Kadlub and Puget share senior authorship of this work. 

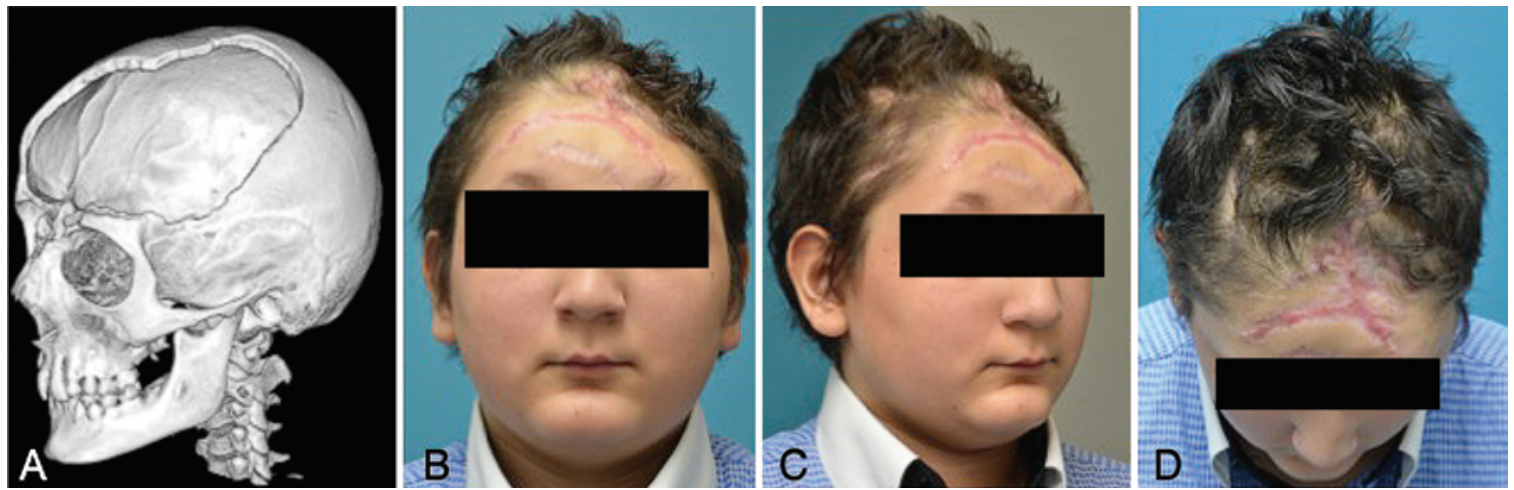

FIG. 1. Preoperative evaluation of the surface of the bone defect on a 3D CT scan (A) and of the external deformities and multiple scars (B-D). Figure is available in color online only.

We present herein a 1-stage reconstructive technique using a porous hydroxyapatite (HA) implant and a free latissimus dorsi muscle flap in an 11-year-old patient after craniectomy secondary to a severe traumatic cranial vault injury.

\section{Case Report}

\section{Description of the Initial Lesions}

An 11-year-old male patient was referred to our center for the management of a severe left frontoparietal traumatic skull injury caused by a boat propeller. After acute management in a foreign country, the patient was unconscious on admission to our facility with a Glasgow Coma Scale score of 11 and an anisocoria associated with right hemiplegia. Initial CT scanning showed comminuted skull bone fractures with multiple bone impactions in the frontoparietal area associated with several hemorrhagic contusions of the underlying cortex. Although a DC was performed emergently to relieve intracranial hypertension and to remove impacted bone fragments, paresis of the right upper arm persisted and finally resolved after 3 months. Two weeks postoperatively, nodular frontoparietal cortical collections were detected on cerebral CT and MRI. Although these collections contained an aseptic hematic liquid, prolonged prophylactic antibiotic therapy was introduced. Complete healing of the frontal and scalp wounds was delayed due to skin infection.

\section{Reconstruction of the Defects}

Reconstruction of the scalp and forehead defects was performed in our center 10 months postinjury with a multidisciplinary approach including pediatric neurosurgery, plastic, and maxillofacial teams. At the time of surgery, no skin infection was noted and stable coverage by fibrous tissues had been achieved. A bone defect was located in the left frontoparietal region. Its surface area, evaluated on 3D CT, was $85 \mathrm{~cm}^{2}$ (Fig. 1A). The overlying scalp and forehead skin was sclerotic and atrophic, typical of postlaceration wound healing (Fig. 1B-D). Because of the bone defect complexity and size, an HA implant was custom-made (Fig. 2A) using 3D stereolithography to create a resin model to reproduce the shape of the bone defect. The resin model was then used to produce the HA implant (CustomBone, Fin-Ceramica Faenza S.p.A., CodmanEthicon SAS). The implant porosity was between $60 \%$ and $70 \%$ and contained both macro- and micropores of $200-500 \mu \mathrm{m}$ and $1-10 \mu \mathrm{m}$, respectively.

As all local flap solutions were impossible, implant coverage was ensured by a free latissimus dorsi muscle flap revascularized through an end-to-end microanastomosis on the right superficial temporal pedicle (Fig. 2B-D). The uncovered muscle portion of the latissimus dorsi was left for secondary healing to obtain skin retraction and minimize alopecia (Fig. 3A-C). A thin skin graft, harvested on the contralateral scalp, was performed 15 days postop-
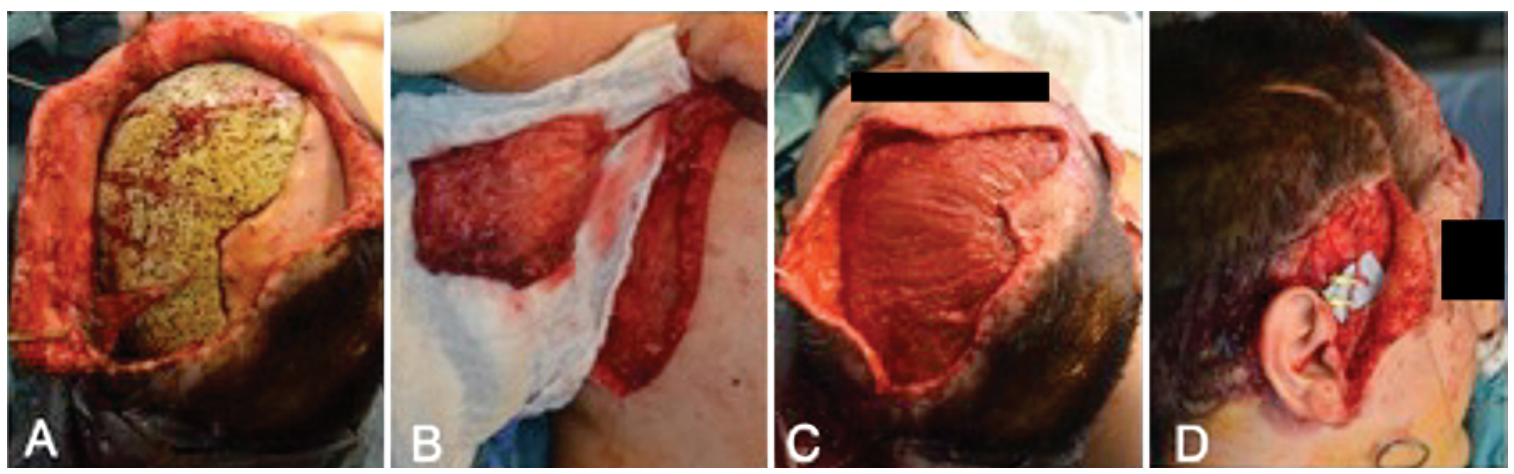

FIG. 2. Intraoperative views of the custom-made porous HA implant (A) covered by the latissimus dorsi muscle free flap (B and C), microanastomosed on the superficial temporal vessels (D). Figure is available in color online only. 

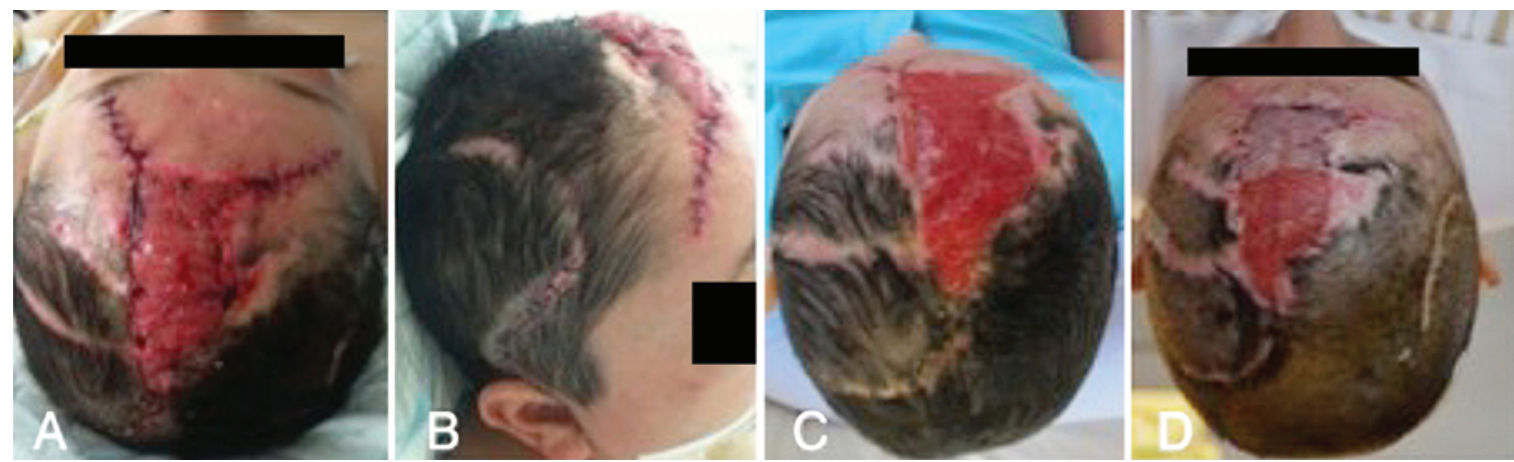

FIG. 3. Postoperative results: immediate (A and $\mathbf{B})$, after 15 days of direct healing $(\mathbf{C})$, and after thin skin grafting on the upper forehead (D). Figure is available in color online only.

eratively to cover the forehead portion of the skin defect (Fig. 3D). Complete and stable healing with no implant exposure as well as an esthetically pleasing cranial vault shape was achieved (Fig. 4A and B). Two years postoperatively, CT scanning showed ossification on the edge of the implant and one focal ossification under the implant. The maximal under-prosthetic bone thickness was 3.06 $\mathrm{mm}$ (Fig. 4C and D). Compressive hydrocolloid dressings were applied over the forehead skin graft to avoid hypertrophic scar. At the 2-year follow-up, the cosmetic result was judged to be satisfactory (Fig. 5A and B).

\section{Discussion}

Reconstruction of skull defects requires collaboration between neurosurgeons and plastic surgeons to choose the most appropriate procedure, especially in growing children. We describe herein a 1-stage reconstructive procedure for a bone and soft tissue defect of the cranial vault secondary to a boat propeller injury in an 11-year-old child.

Reconstruction of skin and bone defects of the skull and forehead is often challenging and requires an accurate preoperative evaluation. To determine the most appropriate surgical procedure, the patient's status and type of defect, including its location, size, and depth, ${ }^{1,16,28}$ must be taken into account. Small and superficial scalp defects can be managed using direct closure or local flaps, but more extensive injuries associated with large calvarial and soft tissue defects may require more complex techniques especially if trophicity of local tissues is compromised. Free tissue transfer is the best choice to replace large scalp defects. ${ }^{8,16}$ Flaps including a skin paddle such as the anterolateral thigh, latissimus dorsi muscle, rectus abdominis muscle, and radial forearm are the most popular free flaps used for scalp and forehead reconstruction. ${ }^{16}$ Their major advantage is the provision of a large surface area for coverage and a long pedicle, ${ }^{4}$ allowing tension-free microanastomosis on the superficial temporal pedicle. These vessels represent the best and perhaps the only option for direct anastomosis and avoid the more challenging and less reliable interposition graft or vascular loop techniques. ${ }^{14}$ However, free flaps can present several disadvantages as well. Their skin component fixes the scalp defect and creates a stable zone of alopecia. Musculocutaneous flaps, depending on the morphological development of the child, may be too bulky. In such situations, we favor a pure muscle flap, especially the latissimus dorsi muscle flap, as it provides a large and regular tissue covering that returns the cranial vault to a more harmonious shape with time and allows scar retraction while minimizing the alopecic area.

Scalp reconstruction has 2 main objectives: protect the brain and restore harmonious skull contours with hairbearing tissues. ${ }^{6}$ Tissue expansion meeting these 2 criteria represents a first choice option as reported by Akamatsu et al. in an 8-year-old child ${ }^{2}$ and by Carloni et al. in
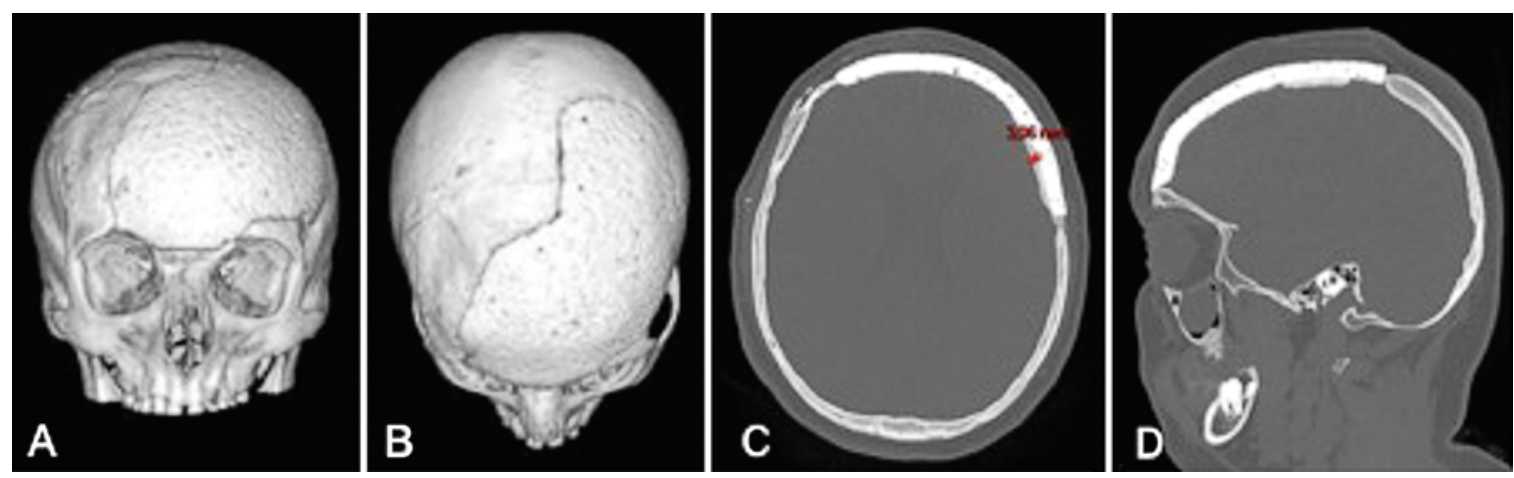

FIG. 4. Two-year postoperative results: 3D CT scans (A and B) and evaluation of the maximal under-prosthetic bone thickness on axial (C) and sagittal (D) CT scans. Figure is available in color online only. 


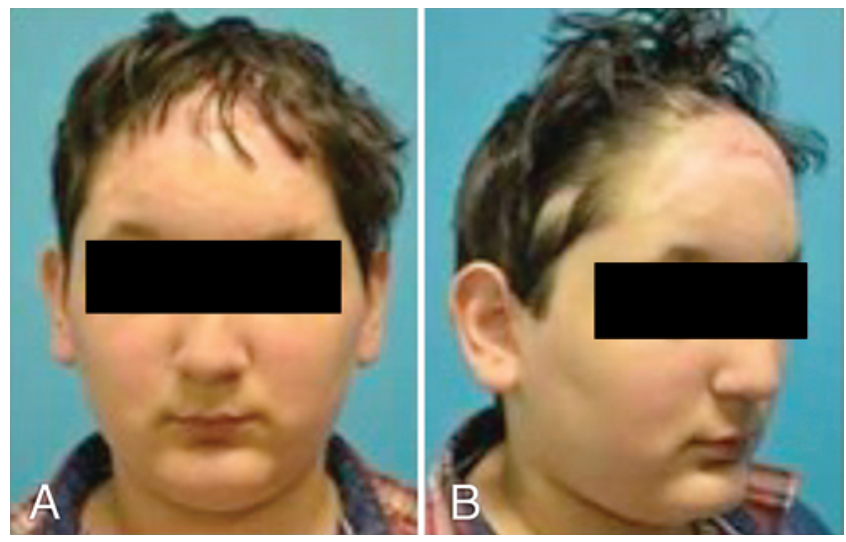

FIG. 5. Two-year postoperative results: morphological aspect. Figure is available in color online only.

adults $^{7}$ and should be favored whenever possible. However, pushing its indications may lead to several postoperative complications such as implant exposure, flap necrosis, or alopecia. ${ }^{3,20,21}$ Its use is limited by the amount and quality of the remaining hair-bearing tissues. An expander placed under fibrotic tissues can lead to ischemic ulceration,, 10 increasing the risk of implant exposure. Thus, it is necessary to place it entirely under a well-vascularized and stretchable skin.,10 The traumatic scalp laceration and infectious history in our case prevented us from using this solution. A free tissue transfer was the only reliable option in our 11-year-old patient, and we favored a free latissimus dorsi muscle flap for 2 main reasons. First, the boy was overweight and we were concerned about the unpleasant appearance that would be created by a bulky flap. Second, we were expecting a large skin defect and wanted to count on the retraction of secondary healing to reduce the alopecic area. After 15 days of granulation, only a small thin skin graft was necessary to cover the remaining non-hairbearing area of the forehead.

The timing of and the choice of material to use in the $\mathrm{CP}$ are essential parameters for the success of the reconstruction. In our case, the $\mathrm{CP}$ was performed with a custom-made porous HA implant 10 months after the injury when complete resolution of skin infections and a stable skin covering were obtained. Thus, we experienced no postoperative complications. The optimal timing of reconstructive surgery, in cases requiring secondary $\mathrm{CP}$, is hard to define and is the subject of controversy according to data available in the literature. Schuss et al. reported on a series of more than $200 \mathrm{CPs} .{ }^{24}$ The timing of CP after craniectomy had no significant influence on outcome in their study. A recent meta-analysis showed that early $\mathrm{CP}$ does not influence the rate of $\mathrm{CP}$ infection. ${ }^{22,31}$ Like Larrañaga et al., ${ }^{16}$ we recommend performing the CP simultaneously with the soft tissue repair, provided that there is no underlying infection. Otherwise, the CP should be delayed for a secondary procedure. ${ }^{1,16}$ The ideal material for $\mathrm{CP}$ is also a controversial issue. Besides an autologous bone graft, various types of synthetic material are used, including polymethylmethacrylate (PMMA), HA, titanium, polyethylene, polyetheretherketone (PEEK), and glass fiber-reinforced composite (FRC) ${ }^{18,23}$ However, few studies have provided objective data on the most appropriate material to use in CP. Recent studies have reported higher rates of complications with autologous bone versus alloplastic material, ${ }^{13,23}$ in particular with HA and FRC implants. ${ }^{23}$ Hydroxyapatite implants have garnered particular attention. ${ }^{11,13,18,19,23,26,27}$ Their reported adverse effects rate from large series (more than 1500 patients $\left.^{26,27}\right)$ is among the lowest $(<6 \%)$, and their osteo-compatibility and porous structure have been proposed as an explanation. ${ }^{23}$ But they also have disadvantages. A higher epidural hematoma rate, as compared with that using titanium, has been reported by Lindner et al., ${ }^{19}$ although their infection rate was not statistically different. They are also more fragile, and several postoperative breakages have been described. ${ }^{26}$ In our case, several reasons made us choose a custom-made porous HA implant over other available materials. First, we found its osteo-induction potential appealing given the large size of the bone defect $\left(85 \mathrm{~cm}^{2}\right)$, especially in a growing child. After only 2 years postsurgery, it is hard to draw conclusions. The maximal under-prosthetic bone thickness was $3.06 \mathrm{~mm}$ in a relatively small area, corresponding to a score of 1 in the Hardy classification..$^{11}$ But, like Hardy et al., we were unable to determine the osteo-integration of the implant on conventional CT as bone density is lower than that of the implant. ${ }^{11}$ Note that the advent of CADCAM has simplified the modeling of these implants, thus decreasing operative time and implant breakage ${ }^{25}$ and/or misshapen rate.

A harmonious cranial vault shape was restored without any postoperative complications. Nevertheless, revisions will be necessary to improve the fibrotic appearance of the forehead scar and reduce the alopecic area.

\section{Conclusions}

Our results suggest that concomitant reconstruction of a large calvarial defect by $\mathrm{CP}$ with a custom-made HA implant covered by a free latissimus dorsi muscle flap is a safe and efficient procedure in children, provided that there is no underlying infection of the operative site.

\section{References}

1. Afifi A, Djohan RS, Hammert W, Papay FA, Barnett AE, Zins JE: Lessons learned reconstructing complex scalp defects using free flaps and a cranioplasty in one stage. J Craniofac Surg 21:1205-1209, 2010

2. Akamatsu T, Hanai U, Kobayashi M, Nakajima S, Kuroki $\mathrm{T}$, Miyasaka M, et al: Cranial reconstruction in a pediatric patient using a tissue expander and custom-made hydroxyapatite implant. Tokai J Exp Clin Med 40:76-80, 2015

3. Antonyshyn O, Gruss JS, Mackinnon SE, Zuker R: Complications of soft tissue expansion. Br J Plast Surg 41:239250, 1988

4. Beasley NJP, Gilbert RW, Gullane PJ, Brown DH, Irish JC, Neligan PC: Scalp and forehead reconstruction using free revascularized tissue transfer. Arch Facial Plast Surg 6:1620, 2004

5. Bobinski L, Koskinen LOD, Lindvall P: Complications following cranioplasty using autologous bone or polymethylmethacrylate - retrospective experience from a single center. Clin Neurol Neurosurg 115:1788-1791, 2013

6. Broyles JM, Abt NB, Shridharani SM, Bojovic B, Rodriguez ED, Dorafshar AH: The fusion of craniofacial reconstruction 
and microsurgery: a functional and aesthetic approach. Plast Reconstr Surg 134:760-769, 2014

7. Carloni R, Hersant B, Bosc R, Le Guerinel C, Meningaud JP: Soft tissue expansion and cranioplasty: For which indications? J Craniomaxillofac Surg 43:1409-1415, 2015

8. Chang KP, Lai CH, Chang CH, Lin CL, Lai CS, Lin SD: Free flap options for reconstruction of complicated scalp and calvarial defects: report of a series of cases and literature review. Microsurgery 30:18-30, 2009

9. Coulter IC, Pesic-Smith JD, Cato-Addison WB, Khan SA, Thompson D, Jenkins AJ, et al: Routine but risky: a multicentre analysis of the outcomes of cranioplasty in the Northeast of England. Acta Neurochir (Wien) 156:1361-1368, 2014

10. Gürlek A, Alaybeyoğlu N, Demir CY, Aydoğan H, Bilen BT, Oztürk A: Aesthetic reconstruction of large scalp defects by sequential tissue expansion without interval. Aesthetic Plast Surg 28:245-250, 2004

11. Hardy H, Tollard E, Derrey S, Delcampe P, Péron JM, Fréger $\mathrm{P}$, et al: Tolérance clinique et degré d'ossification des cranioplasties en hydroxyapatite de larges défects osseux. Neurochirurgie 58:25-29, 2012

12. Honeybul S, Ho KM: Long-term complications of decompressive craniectomy for head injury. J Neurotrauma 28:929-935, 2011

13. Iaccarino C, Viaroli E, Fricia M, Serchi E, Poli T, Servadei F: Preliminary results of a prospective study on methods of cranial reconstruction. J Oral Maxillofac Surg 73:23752378, 2015

14. Ioannides C, Fossion E, McGrouther AD: Reconstruction for large defects of the scalp and cranium. J Craniomaxillofac Surg 27:145-152, 1999

15. Joseph V, Reilly P: Syndrome of the trephined. J Neurosurg 111:650-652, 2009

16. Larrañaga J, Rios A, Franciosi E, Mazzaro E, Figari M: Free flap reconstruction for complex scalp and forehead defects with associated full-thickness calvarial bone resections. Craniomaxillofac Trauma Reconstr 5:205-212, 2012

17. Lee CH, Chung YS, Lee SH, Yang HJ, Son YJ: Analysis of the factors influencing bone graft infection after cranioplasty. J Trauma Acute Care Surg 73:255-260, 2012

18. Lin AY, Kinsella CR Jr, Rottgers SA, Smith DM, Grunwaldt LJ, Cooper GM, et al: Custom porous polyethylene implants for large-scale pediatric skull reconstruction: early outcomes. J Craniofac Surg 23:67-70, 2012

19. Lindner D, Schlothofer-Schumann K, Kern BC, Marx O, Müns A, Meixensberger J: Cranioplasty using custom-made hydroxyapatite versus titanium: a randomized clinical trial. J Neurosurg 26:1-9, 2016

20. Newman MI, Hanasono MM, Disa JJ, Cordeiro PG, Mehrara BJ: Scalp reconstruction: a 15-year experience. Ann Plast Surg 52:501-506, 2004

21. Nguyen Van Nuoi V, Francois-Fiquet C, Diner P, Sergent B, Zazurca F, Franchi G, et al: Nævus pigmentaires congénitaux géants: quelle place pour l'expansion cutanée. Ann Chir Plast Esthet 59:240-245, 2014

22. Piedra MP, Ragel BT, Dogan A, Coppa ND, Delashaw JB: Timing of cranioplasty after decompressive craniectomy for ischemic or hemorrhagic stroke. J Neurosurg 118:109-114, 2013

23. Piitulainen JM, Kauko T, Aitasalo KMJ, Vuorinen V, Vallittu PK, Posti JP: Outcomes of cranioplasty with synthetic materials and autologous bone grafts. World Neurosurg 83:708-714, 2015

24. Schuss P, Vatter H, Marquardt G, Imöhl L, Ulrich CT, Seifert V, et al: Cranioplasty after decompressive craniectomy: the effect of timing on postoperative complications. J Neurotrauma 29:1090-1095, 2012

25. Staffa G, Nataloni A, Compagnone C, Servadei F: Custom made cranioplasty prostheses in porous hydroxy-apatite using 3D design techniques: 7 years experience in 25 patients. Acta Neurochir (Wien) 149:161-170, 2007

26. Stefini R, Esposito G, Zanotti B, Iaccarino C, Fontanella MM, Servadei F: Use of "custom made" porous hydroxyapatite implants for cranioplasty: postoperative analysis of complications in 1549 patients. Surg Neurol Int 4:12, 2013

27. Stefini R, Zanotti B, Nataloni A, Martinetti R, Scafuto M, Colasurdo M, et al: The efficacy of custom-made porous hydroxyapatite prostheses for cranioplasty: evaluation of postmarketing data on 2697 patients. J Appl Biomater 13:e136e144, 2014

28. van Driel AA, Mureau MAM, Goldstein DP, Gilbert RW, Irish JC, Gullane PJ, et al: Aesthetic and oncologic outcome after microsurgical reconstruction of complex scalp and forehead defects after malignant tumor resection: an algorithm for treatment. Plast Reconstr Surg 126:460-470, 2010

29. Wachter D, Reineke K, Behm T, Rohde V: Cranioplasty after decompressive hemicraniectomy: underestimated surgery-associated complications? Clin Neurol Neurosurg 115:1293-1297, 2013

30. Wiggins A, Austerberry R, Morrison D, Ho KM, Honeybul S: Cranioplasty with custom-made titanium plates -14 years experience. Neurosurgery 72:248-256, 2013

31. Yadla S, Campbell PG, Chitale R, Maltenfort MG, Jabbour P, Sharan AD: Effect of early surgery, material, and method of flap preservation on cranioplasty infections: a systematic review. Neurosurgery 68:1124-1130, 2011

\section{Disclosures}

The authors report no conflict of interest concerning the materials or methods used in this study or the findings specified in this paper.

\section{Author Contributions}

Conception and design: Puget, Morice, Kadlub. Acquisition of data: Morice. Analysis and interpretation of data: Morice. Drafting the article: Morice. Critically revising the article: Kadlub. Reviewed submitted version of manuscript: Kadlub. Approved the final version of the manuscript on behalf of all authors: Puget. Performed surgery: Kolb. Managed patient: Picard.

\section{Correspondence}

Stéphanie Puget, Department of Pediatric Neurosurgery, Hopital Necker, Paris Cité Sorbonne, 149 Rue de Sèvres, Paris 75015, France. email: stephanie.puget@gmail.com. 